GUEST EDITORIAL

\title{
Meeting the complex needs of individuals with rare genetic disorders in South Africa - lessons from tuberous sclerosis complex
}

Every year, 28 February is Rare Disease Day around the globe. In many high-income countries, significant programmes of research and policy have been developed to understand and meet the needs of individuals who live with rare diseases. In South Africa (SA), rare diseases have unfortunately not reached the awareness of most policy-makers and health system planners. On the one hand, it seems relatively easy to understand why rare diseases have remained 'rare' in SA, given the very high burden of other diseases, both communicable and non-communicable. On the other hand, we may be able to learn a lot by studying and treating rare disorders, sometimes with profound clinical consequences.

A careful look will identify many lessons we can learn from rare diseases. ${ }^{[1]}$ Rare diseases are defined as conditions that have a prevalence less than $1 / 2000$. To date between 6000 and 8000 rare diseases have been identified, with characteristics that include a broad range of physical manifestations (e.g. renal, lung, cardiac and central nervous system involvement), neurodevelopmental manifestations (e.g. intellectual disability, autism, specific learning disorders) and mental health disorders (e.g. depression, psychosis and anxiety disorders). The first lesson, therefore, is that while these diseases are individually rare, they are collectively quite common, occurring in perhaps as many as 1 in 20 individuals at some point in their life. The second lesson is that many rare diseases share common pathophysiological mechanisms. A new discovery in one rare disorder may therefore also have a direct impact on another. The tuberous sclerosis complex (TSC) story is a case in point here. The third lesson is that the study of rare diseases can lead to improved understanding of common diseases. ${ }^{[1]}$ A perfect example here is the relationship between trisomy 21 (Down syndrome) and high rates of Alzheimer's disease, which led to the discovery of the molecular basis of familial Alzheimer's. ${ }^{[2]}$

An important feature of the majority of rare diseases is that they are chronic conditions, typically lifelong. Not only that, but many rare genetic disorders are also associated with multi-system involvement, sometimes referred to as 'chronic multi-morbidity. ${ }^{[3]}$ There is global acknowledgement of the needs of individuals with chronic conditions, and a strong imperative from the World Health Organization for all countries to meet these chronic needs. ${ }^{[4]}$ However, it is clear that, even with good policies, there is a mismatch between policy and implementation in the majority of low- and middle-income countries, including SA. ${ }^{[3,5,6]}$

So, what about TSC? TSC is a rare genetic disorder, associated with very obvious 'chronic multi-morbidity' (see de Vries et al. ${ }^{[7]}$ in this issue of $S A M J$ ). The majority of individuals with TSC are diagnosed in the first few years of life, but some are not diagnosed until adolescence or adulthood. Most people with TSC will have involvement of the brain, skin and kidneys, and almost all will have some TSC-associated neuropsychiatric disorders (TAND), including a wide range of behavioural, psychiatric, neurodevelopmental, scholastic and psychosocial difficulties. ${ }^{[8]}$ With a birth incidence of 1 in 6000 TSC is relatively common for a rare disorder, but the majority of healthcare professionals will nevertheless see no or perhaps one case in their professional career. The disorder remained relatively obscure until the early 2000s, when the molecular mechanisms of TSC were identified, showing that the two proteins directly affected, TSC1 and TSC2, are key regulators in a fundamental intracellular signalling pathway, the mTOR (mammalian target of rapamycin) pathway. ${ }^{[7]}$ This pathophysiological discovery led remarkably rapidly to the identification of molecularly targeted treatments for TSC - medications that specifically and directly inhibit mTOR to reduce the overactivation resulting from deficits in TSC1 or TSC2 proteins. The mTOR proteins have since also been shown to be involved in neurofibromatosis type 1 and fragile X syndrome (two other rare genetic disorders), in response to cannabis (a rather common phenomenon), and in longevity. ${ }^{[-12]}$

The clinical challenges for individuals with TSC, however, remain. Given that most healthcare professionals will never have diagnosed or treated someone with TSC, people are undiagnosed, misdiagnosed or diagnosed very late. Treatment is often inadequate or wrong. For example, a recent case report ${ }^{[13]}$ in the $S A M J$ was clearly a case of an adolescent with TSC, facial angiofibromas and a presumed fat-poor angiomyolipoma (a non-cancerous tumour that should be treated with an mTOR inhibitor). However, this would have been obvious only to professionals who have seen and treated numerous individuals with TSC.

An interdisciplinary group of clinicians and TSC researchers have recognised the significant challenges of living with TSC in SA (and other low-resource countries). We acknowledge that these rare genetic disorders are not health priorities in SA, even though a systematic approach to the chronic multi-morbidity of rare diseases would probably lead to significant cost savings and improvements in quality of life for people with TSC. However, conscious that there were well-regarded international consensus guidelines for the diagnosis, monitoring and treatment of TSC, ${ }^{[14,15]}$ we set out to draft a clinical update summarising an evidence-based and international consensus approach to the assessment and treatment of TSC. ${ }^{[7]}$

We realised that the majority of people with TSC in SA are probably cared for by general practitioners, and only a few by specialists. For that reason, we were keen to generate a broad and general document that we hoped would assist general practitioners, specialists, families and individuals with TSC. As one of our anonymous reviewers said, 'The document is about creating awareness and clinical support to fellow clinicians.'

15 May every year is Tuberous Sclerosis Complex Global Awareness Day. We sincerely hope that this editorial and the CME article published in this issue of $S A M J$ will help to raise awareness of TSC, while at the same time reminding us of the needs of all South Africans who live with chronic, multi-morbid rare genetic disorders.

\section{Petrus J de Vries}

Division of Child and Adolescent Psychiatry, Faculty of Health

Sciences, University of Cape Town, South Africa

petrus.devries@uct.ac.za

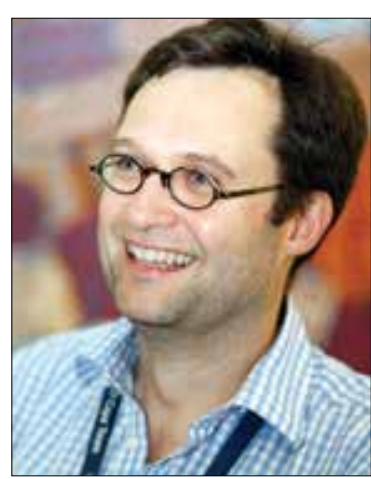


1. Roubertoux PL, de Vries PJ. From molecules to behavior: Lessons from the study of rare genetic disorders. Behav Genet 2011;41(3):341-348. http://dx.doi.org/10.1007/s10519-011-9469-y

2. Isacson O, Seo H, Lin L, Albeck D, Granholm AC. Alzheimer's disease and Down's syndrome: Roles of APP, trophic factors and ACh. Trends Neurosci 2002;25(2):79-84. http://dx.doi.org/10.1016/S0166of APP, trophic factor

3. Oni T, McGrath N, BeLeu R, et al. Chronic diseases and multi-morbidity - a conceptual modification to the WHO ICCC model for countries in health transition. BMC Public Health 2014;14:575. http:/ dx.doi.org/10.1186/1471-2458-14-575

4. World Health Organization. Innovative Care for Chronic Conditions: Building Blocks for Action. Geneva: WHO, 2002

5. Hofman K. Non-communicable diseases in South Africa: A challenge to economic development. S Afr Med J 2014;104(10):647. http://dx.doi.org/10.7196/SAMJ.8727

6. Draper CA, Draper CE, Bresick GF. Alignment between chronic disease policy and practice: Case study at a primary care facility. PLoS One 2014;9(8):e105360. http://dx.doi.org/10.1371/journal. pone.0105360

7. De Vries PJ, Leclezio L, Wilmshurst JM, et al. Diagnosis, monitoring and treatment of tuberous sclerosis complex (TSC): A South African consensus response to international guidelines. S Afr Med J 2017;107(5):368-378. http://dx.doi.org/10.7196/SAMJ.2017.v107i5.12447

8. De Vries PJ, Whittemore VH, Leclezio L, et al. Tuberous sclerosis associated neuropsychiatric disorders (TAND) and the TAND Checklist. Pediatr Neurol 2015;52(1):25-35. http://dx.doi.org/10.1016/j. pediatrneurol.2014.10.00
9. Johannessen CM, Reczek EE, James MF, Brems H, Legius E, Cichowski K. The NF1 tumor suppressor critically regulates TSC2 and mTOR. Proc Natl Acad Sci USA 2005;102(24):8573-8578. http://dx.doi. org/10.1073/pnas.0503224102

10. Sharma A, Hoeffer CA, Takayasu Y, et al. Dysregulation of mTOR signaling in fragile X syndrome. J Neurosci 2010;30(2):694-702. http://dx.doi.org/10.1523/JNEUROSCI.3696-09.2010

11. Gomez O, Sanchez-Rodriquez A, Le MQU, Sanchez-Caro C, Molina-Holgado F, Molina-Holgadi E. Cannabinoid receptor agonists modulate oligodendrocyte differentiation by activating PI3K/Akt in the mammalian target of rapamycin (mTOR) pathways. Br J Pharmacol 2011;163(7):1520-1532. http:// dx.doi.org/10.1111/j.1476-5381.2011.01414.x

12. Ehninger D, Neff F, Xie K. Longevity, aging and rapamycin. Cell Mol Life Sci 2014;71(22):4325-4346. https://dx.doi.org/10.1007\%2Fs00018-014-1677-1

3. Rood JW, Mokhobo KP. A case of renal cell carcinoma and angiomyolipoma in an adolescent girl. S Afr Med J 2016;106(8):795-796. http://dx.doi.org/10.7196/SAMJ.2016.v106i8.10519

14. Northrup H, Krueger DA, Roberds S, et al. Tuberous sclerosis complex diagnostic criteria update: Recommendations from the 2012 International Tuberous Sclerosis Complex Consensus Conference. Pediatr Neurol 2013;49(4):243-254. http://dx.doi.org/10.1016/j.pediatrneurol.2013.08.001

15. Krueger DA, Northrup H, Roberds S, et al. Tuberous sclerosis complex surveillance and management: Recommendations of the 2012 International Tuberous Sclerosis Complex Consensus Conference.
Rentions Recommendations of the 2012 International Tuberous Sclerosis Complex Consensus Conf
Pediatr Neurol 2013;49(4):255-265. http://dx.doi.org/10.1016/j.pediatrneurol.2013.08.002

S Afr Med J 2017;107(5):366-367. DOI:10.7196/SAMJ.2017.v107i5.12488 